Rocha, F.; Barbosa, F.P.; Abessa, D.M.S. Trilha ecológica como instrumento de Educação Ambiental: estudo de caso e proposta de adequação no Parque Estadual Xixová-Japuí (SP). Revista Brasileira de Ecoturismo, São Paulo, v.3, n.3, 2010, pp.478-497.

\title{
Trilha ecológica como instrumento de Educação Ambiental: estudo de caso e proposta de adequação no Parque Estadual Xixová-Japuí (SP)
}

\section{Fernanda Rocha, Fabiana Pestana Barbosa, Denis Moledo de Souza Abessa}

\section{RESUMO}

Neste trabalho, foi realizado um diagnóstico das condições e da estrutura de uma triIha ecológica situada no Parque Estadual Xixová-Japuí, e soluções foram propostas para os problemas encontrados. Foram realizadas três visitas ao Parque, entre 2005 e 2008, nas quais a trilha foi analisada em relação às condições de segurança, estado de conservação, facilidade de circulação e sinalização. Para facilitar a análise e a posterior proposição de melhorias, a trilha foi dividida em seis trechos, de acordo com as principais características encontradas. Todos os trechos foram considerados como apresentando baixa comodidade ou de risco para os visitantes e necessitam de melhorias na infra-estrutura, tais como corrimões e escadas, sistemas de drenagem da água, lixeiras, placas informativas e delimitação do caminho existente. Para que a trilha ecológica seja viabilizada para o uso público em conformidade com os objetivos do parque, outros setores do parque devem ser também recuperados ou modificados, e outras estruturas de apoio devem ser implantadas. Com a adoção de infraestrutura completa para o recebimento de visitantes, o Parque poderá constituir um importante local para recreação e educação ambiental na Baixada Santista.

PALAVRAS-CHAVE: Parque Estadual Xixová-Japuí, Conservação, Trilha Ecológica.

Ecological trails as Environmental Education tool: case study and correction proposal for the Parque Estadual Xixová-Japuí, SP, Brazil.

\begin{abstract}
This paper presents a diagnosis of the conditions and structure of an ecological trail in Parque Estadual Xixová-Japuí (PEXJ), and the proposal of solutions to the detected problems. Three visits to the trail were paid specifically for this analysis, between 2005 and 2008, in which the trail was evaluated in its security conditions, conservation degree, accessibility for visitors and signage conditions. To provide a better evaluation, the trail was divided into six segments, according to their characteristics. All the trail segments presented low comfort or risks to the visitors and needed infra-structure improvements, such as the installation of stairways and handrails, drainage system, dumpers, signs and path delimitations. In order to make the trail viable for public use in accordance with the objectives of the park, other PEXJ sectors must be recovered or modified, and new support structures must be installed. If appropriate infra-structure to receive visitors is implemented, the park could constitute an important site for recreation and environmental education.
\end{abstract}

KEYWORDS: Parque Estadual Xixová-Japuí; Conservation; Ecological Trail. 
Trilha ecológica como instrumento de Educação Ambiental: estudo de caso e proposta de adequação no Parque Estadual Xixová-Japuí (SP).

\section{Introdução}

A Mata Atlântica é um bioma florestal que se estende praticamente por todo o litoral brasileiro, ocorrendo nas encostas do planalto atlântico e nas baixadas litorâneas contíguas, desde a costa nordeste até o litoral sul do Brasil. Engloba um diversificado mosaico de ecossistemas que acompanha a diversidade de ambientes da vasta região onde ocorre. Muito rica em espécies, inclusive endêmicas, essa floresta recobria de modo quase contínuo a faixa paralela ao litoral, mas hoje corresponde a um dos biomas mais degradados e ameaçados no mundo, já que a maior parte dos ecossistemas naturais foi eliminada ao longo de diversos ciclos desenvolvimentistas. Hoje, a especulação imobiliária, a pressão demográfica e a ocupação desordenada são alguns dos fatores que mais estimulam a degradação ambiental da Mata Atlântica (OLIVA, 2003).

Frente ao quadro crescente de supressão, degradação e fragmentação da Mata Atlântica, o estabelecimento e a implantação de um sistema de unidades de conservação adequado e eficiente é uma das estratégias de sucesso que vem sendo posta em prática visando à conservação da diversidade biológica desse bioma. Tal estratégia deve estar inserida dentro de políticas para a conservação, fundamentadas em sólidas bases científicas e em um espectro participativo cada vez mais necessário, porém consciente e coerente. Nesse contexto, para a maioria das áreas protegidas, sua organização deve ser tal, que englobe locais intocáveis e ao mesmo tempo preveja a existência de áreas destinadas a alguns tipos de uso, como turismo e lazer, educação, pesquisa, entre outros.

O Parque Estadual Xixová-Japuí (PEXJ) está localizado na Baixada Santista, litoral do Estado de São Paulo (Figura 1), e foi criado no intuito de preservar uma região remanescente de Mata Atlântica, bastante atingida por impactos ambientais resultantes de intensa ocupação urbana, de industrialização e de atividades portuárias. O PEXJ foi criado pelo Decreto Estadual $n^{\circ} 37.536$ de 27/09/1993 (SÃO PAULO, 1993), e é administrado pela Fundação Florestal (FF), órgão vinculado à Secretaria do Meio Ambiente do Estado de São Paulo (SMA-SP). Essa unidade de conservação (UC) possui 901,0 hectares de área, abrangendo os municípios de São Vicente (347 ha) e Praia Grande (554 ha), inserindo-se em uma zona urbana e distando em 75 quilômetros da capital do Estado. A Fase 1 de seu plano de manejo (SÃO PAULO, 1997) foi parcialmente efetivada, resultando em uma gestão bastante precária na primeira década. Atualmente o parque entrou em uma nova etapa de gestão, com a implementação do Conselho Consultivo e a elaboração da Fase 2 do plano de manejo, a partir de estudos técnicos muito mais detaIhados, os quais permitirão a gestão adequada do PEXJ e de seu patrimônio natural. 


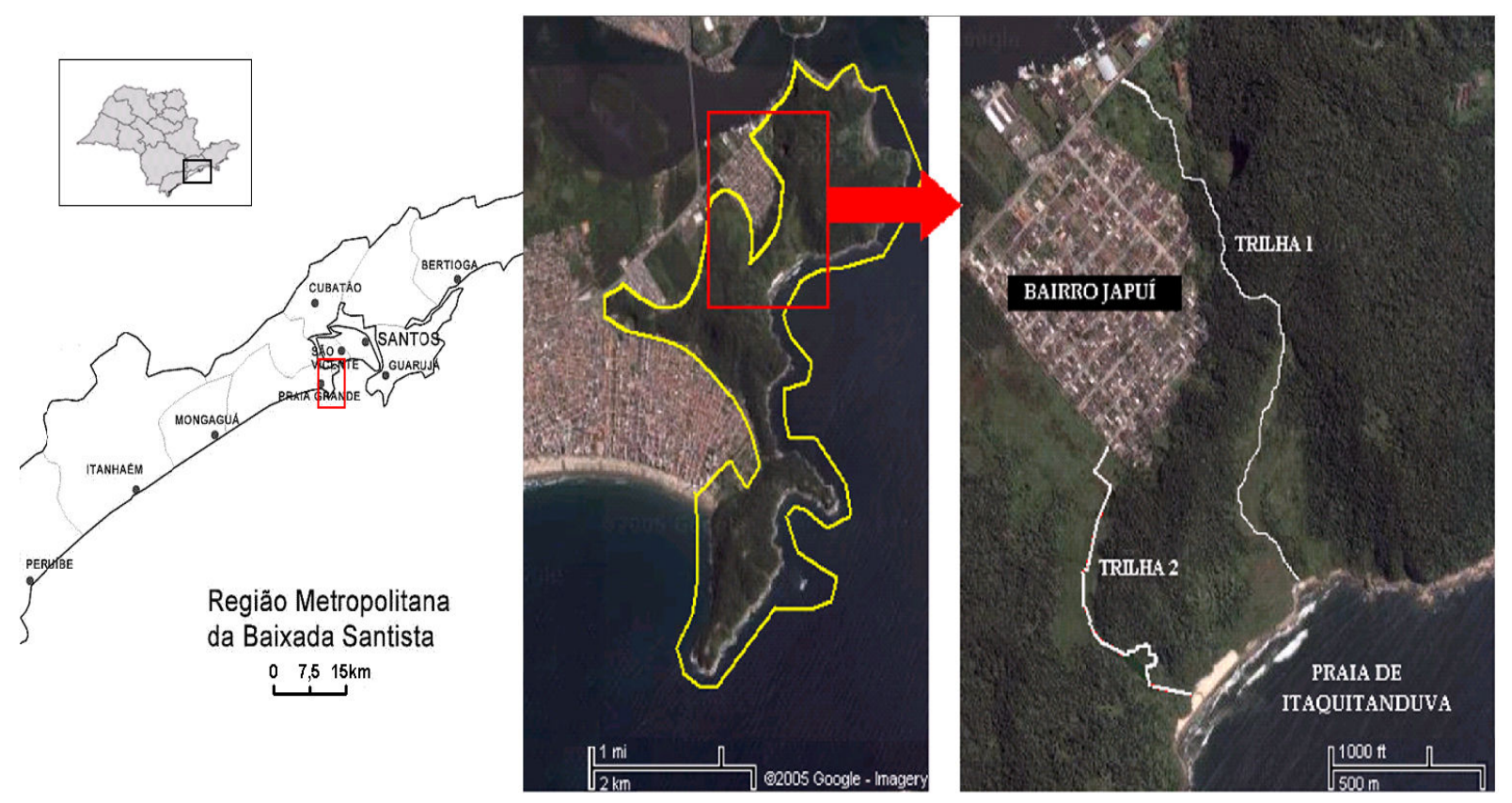

Figura 1. Mapa de localização do PEXJ e localização das Trilhas 1 e 2. Adaptado pelos autores de IGC-SP (2007) e Google (2005).

Dois terços da área do parque englobam áreas terrestres, e o restante é constituído pela porção marinha. A porção terrestre do parque representa importante fragmento de mata atlântica da Baixada Santista, destacado da Serra do Mar, e desempenha importantes funções ecológicas, especialmente como área de pouso, reprodução e alimentação de aves migratórias (SÃO PAULO, 1997). Além de Mata Atlântica, ocorrem dentro do parque os ecossistemas de Restinga, Capoeiras, Costões Rochosos e Praias Arenosas (SÃO PAULO, 1997).

Algumas Organizações Não-Governamentais (ONG) atuam especificamente na área do PEXJ, com destaque para a ONG Alma Verde - SOS Itaquitanduva, que foi fundada em 2000 e desenvolve projetos sociais (oficinas de costura, escolinha de surf, reforço escolar, entre outros) e ambientais (caminhadas ecológicas, multirão de limpeza da praia de Itaquitanduva, atividades de educação ambiental, entre outros) na região do parque e em seu entorno (ALMA VERDE, 2008). Outras ONG também possuem interesse em atuar no local, principalmente com projetos de ecoturismo, educação ambiental e capacitação da população, porém esbarraram historicamente nos problemas de gestão e infraestrutura do próprio parque, que acabaram sendo fatores impeditivos à condução de projetos.

De acordo com a sua categoria de UC, o PEXJ deve ter como objetivo básico a preservação permanente de ecossistemas naturais de grande relevância ecológica e beleza cênica, possibilitando a realização de pesquisas científicas e o desenvolvimento de atividades de educação e interpretação ambiental, de recreação em contato com a natureza e de turismo ecológico. O Sistema Nacional de Unidades de Conservação 
Trilha ecológica como instrumento de Educação Ambiental: estudo de caso e proposta de adequação no Parque Estadual Xixová-Japuí (SP).

(SNUC), Lei Federal $n^{\circ}$ 9985/00 (BRASIL, 2000), estabelece que atividades educativas, recreativas e de interpretação ambiental devem ser promovidas pelas UC, seguindo os propósitos de cada categoria de manejo. Uma das maneiras de atingir tais objetivos se dá por meio da visitação, que propicia ao visitante a oportunidade de conhecer, de forma lúdica, os atributos e valores ambientais protegidos pela UC. A visitação em áreas protegidas, quando bem controlada, pode constituir importante ferramenta nos âmbitos ambiental, social, econômico e político, devendo, portanto, ser utilizada dentro de critérios técnicos bem estabelecidos (MMA, 2006).

De forma geral, as atividades de visitação em UC têm enfrentado alguns problemas, sendo que alguns requerem providências mais urgentes. É possível citar o despreparo de alguns gestores e técnicos que cuidam das atividades de visitação, o número reduzido de funcionários nas UC, a quantidade geralmente insuficiente de recursos financeiros para a implementação e fiscalização das diversas atividades, e a deficiência no planejamento que reúne os atrativos e a comunidade do entorno.

Quando não é feita de maneira planejada, a visitação pode gerar impactos negativos como a degradação do meio ambiente e a descaracterização paisagísti$\mathrm{ca}$, podendo ainda acarretar riscos para os próprios visitantes, além de não satisfazer os objetivos da educação ambiental (BUCKLEY; PANNELL, 1980). Pedrini et al. (2007) mencionam alguns dos impactos produzidos pela visitação descontrolada no Parque Estadual da Ilha Anchieta, no litoral norte de São Paulo, indicando que ações corretivas podem minimizar os problemas. Por outro lado, quando essa atividade é conduzida de forma correta, diversos benefícios podem ser obtidos, como a valorização da UC, a geração de receita para a unidade, o aumento da proteção da UC e a geração de empregos e oportunidades para as comunidades do entorno (BARROS, 2003).

A utilização de trilhas ecológicas com a finalidade de aproveitar os momentos de lazer do visitante para a transmissão de conhecimentos, e vice-versa, é bastante interessante, tanto do ponto de vista recreativo quanto do educativo. Além disso, as trilhas podem representar uma ferramenta útil para o manejo de áreas protegidas, uma vez que concentram o uso mais intenso em uma pequena área da UC, evitando assim que outras áreas mais sensíveis ou ecologicamente importantes sejam afetadas pelo pisoteio ou pela presença humana (MAGRO, 1999). Nesse contexto, a própria trilha percorrida dentro da UC torna-se um local de informação, através de placas, sinais e instruções, além da própria experiência pessoal de contato com o meio; portanto, aproveita-se o percurso para realização da educação ambiental.

Atualmente, as trilhas ecológicas estão previstas dentro da Política Nacional de Educação Ambiental, instituída por meio da Lei Federal nº 9.795, de 27 de abril 
de 1999 (BRASIL, 1999) e existe reconhecimento público da sua importância como ferramenta de educação, interpretação, comunicação e conscientização ambiental (VASCONCELLOS, 2006). Essa autora aponta ainda que "as áreas naturais protegidas oferecem oportunidades únicas para a (re)aproximação das pessoas aos ambientes naturais, aliando conhecimento, reflexões, desafios, afetividade, curiosidade, imaginação e noção de pertencimento, o que facilita o cumprimento dos objetivos da educação ambiental e da conservação da natureza" (VASCONCELLOS, op.cit., p.14-15).

Além dos aspectos relativos aos visitantes, a exploração da atividade do ecoturismo em UC, através da educação e da interpretação ambiental, pode constituir uma oportunidade ímpar para envolver as comunidades locais na gestão da área, sobretudo nas unidades de proteção integral, promovendo acordos entre as populações e as UC e oferecendo alternativas econômicas para as pessoas, fortalecendo assim as redes sociais e a governança local (EAGLES et al., 2002).

Durante a visitação, diversas atividades podem ser desenvolvidas para recreação e educação ambiental. As trilhas interpretativas são alternativas para trabalhos educativos em campo a partir da análise de seus recursos e da interpretação de suas belezas. Nestas trilhas, a própria paisagem é utilizada como recurso didático e, através da interpretação ambiental, os visitantes podem ser informados e sensibilizados sobre a complexa temática ambiental (OLIVEIRA et al, 1999).

Percorrer trilhas coloca os visitantes em contato com locais preservados da UC, e que, muitas vezes só podem ser atingidos através de caminhadas. Esse recurso permite um intenso contato do visitante com os elementos ambientais, possibilitando múltiplos estímulos sensoriais e uma conscientização sobre a importância do meio ambiente, a partir da experiência prática e da reflexão. Essa forma de educação ambiental não formal é uma das que apresenta melhor relação entre custo e benefícios, sendo amplamente utilizada em áreas protegidas ao redor do mundo (FERREIRA, 2005).

No PEXJ, existe uma rede de trilhas, sendo que a maior parte delas hoje é pouco utilizada, estando estas localizadas de maneira dispersa no interior do parque, servindo principalmente aos guardas-parque e sendo usadas também para atividades ilegais, como extração de recursos e caça. Algumas poucas trilhas possuem um uso mais intenso, devido ao acesso mais fácil e também por levarem aos atrativos cênicos, como por exemplo, as praias (Figura 2). Entre elas, destacam-se as duas trilhas que levam à Praia de Itaquitanduva, partindo do bairro do Japuí, em São Vicente (Figura 1), e que, segundo a indicação feita na proposta de plano de manejo Fase-2, serão as trilhas destinadas a um uso intensivo, voltado à recreação, educação e interpretação ambiental. 
Trilha ecológica como instrumento de Educação Ambiental: estudo de caso e proposta de adequação no Parque Estadual Xixová-Japuí (SP).

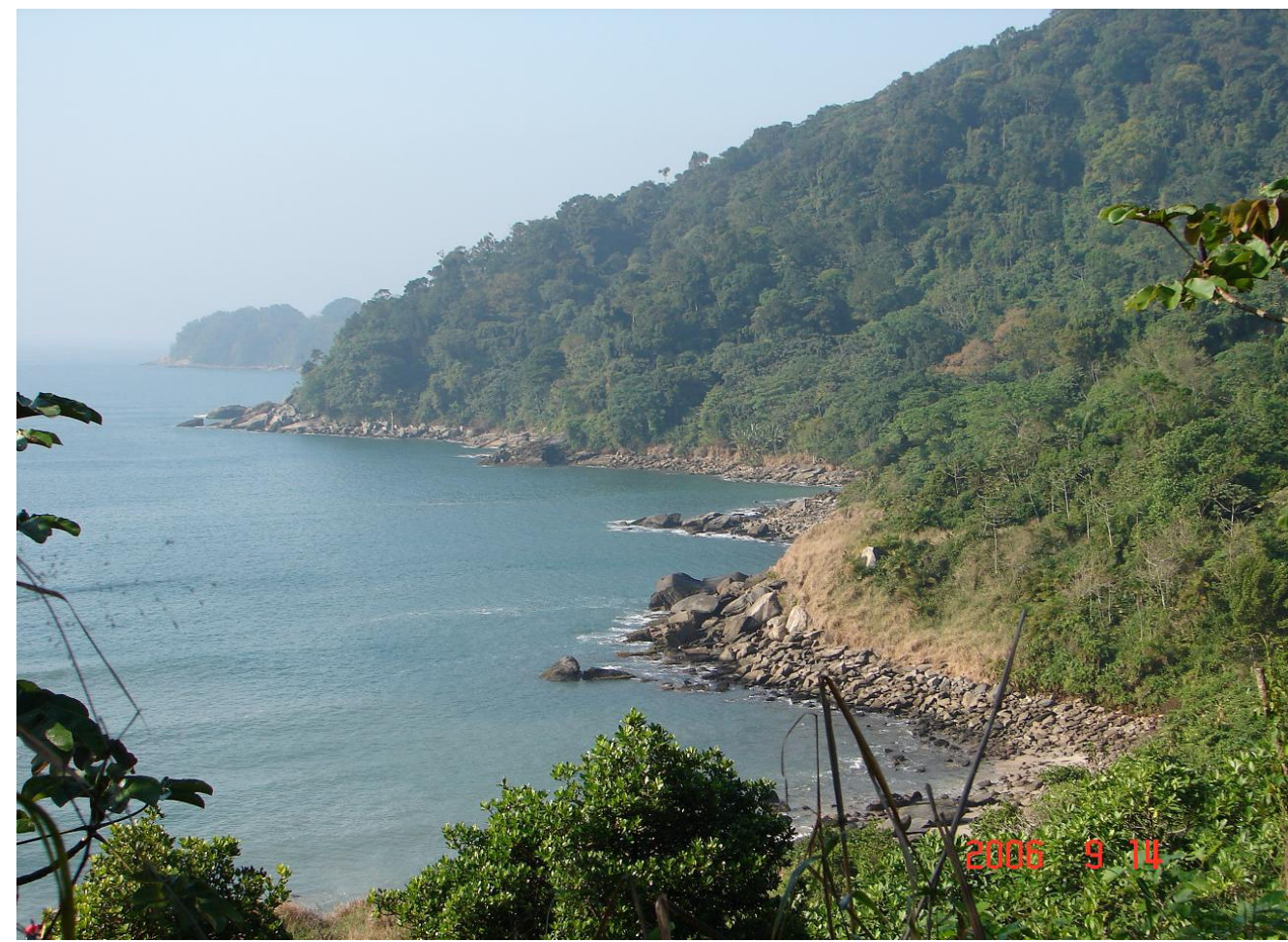

Figura 2. Praia de Itaquitanduva, um dos principais atrativos turísticos do PEXJ, vista da Trilha 2. Foto: F.S.C. Buchmann.

A primeira trilha (Trilha 1 ou Trilha do Curtume), é mais longa e tem início na Avenida Tupiniquins, passando próxima a uma pedreira desativada e ao antigo Curtume Cardamone (ou São Vicente), que se encontra atualmente desativado. Esta trilha atravessa trechos de mata fechada, em um estado mais avançado de regeneração, porém alguns pontos apresentam sinais visíveis de deslizamento do solo. Além disso, os acessos a esse local são precários e carecem de sinalização, o que dificulta o seu uso. Uma segunda trilha (Trilha 2, ou Trilha dos Surfistas), a qual é mais intensamente utilizada por visitantes, parte do fundo do bairro do Japuí e chega até a praia, passando por áreas mais íngremes. Essa trilha possui acesso mais fácil, no entanto os trechos íngremes em ambos os lados são fatores que dificultam o uso público.

Sendo assim, neste trabalho, foi feito um diagnóstico da situação relativa à qualidade ambiental e estrutural da Trilha 2 do PEXJ, e a partir desse diagnóstico foram propostas algumas ações para solucionar os principais problemas levantados, em especial aqueles relativos ao conforto, segurança e educação ambiental, de forma a permitir que estudos posteriores, sobretudo aqueles direcionados para a avaliação da capacidade de carga da trilha (CIFUENTES, 1992), e implantação de sinalização adequada (MAGRO; FREIXÊDAS, 1998), possam orientar um uso público mais apropriado e condizente com o esperado em um parque estadual. 


\section{Materiais e métodos}

A trilha utilizada como objeto de estudo do presente trabalho (identificada como Trilha 2), é relativamente curta, tendo seu início no fundo do bairro do Japuí (São Vicente), ao lado da Pastoral da Criança ( $\left.23^{\circ} 59^{\prime} 34,00606 " \mathrm{~S}, 46^{\circ} 23^{\prime} 36,54922^{\prime \prime W}\right)$, e chegando na porção sul da praia de Itaquitanduva $\left(23^{\circ} 59^{\prime} 48,79828 " S, 46^{\circ}\right.$ $23 ' 27,44821$ "W). Essa trilha é utilizada geralmente por pescadores e coletores, surfistas e banhistas oriundos dos bairros vizinhos e, eventualmente, de outras cidades da Baixada Santista.

Foram realizadas três visitas ao PEXJ, respectivamente em novembro de 2005, setembro de 2006 e outubro de 2008. Nestas visitas, a Trilha 2 foi percorrida e seu percurso analisado em relação às condições de segurança, estado de conservação, facilidade de circulação e sinalização.

Para facilitar a avaliação e a posterior descrição das benfeitorias que devem ser feitas, a trilha foi dividida em trechos de acordo com as principais características encontradas. Com um navegador GPS portátil (Garmin E-trex Legend), foram marcadas as coordenadas geográficas do início de cada trecho e dos locais onde haviam problemas relacionados às condições da trilha. Foram avaliadas também as necessidades de implantação de informações e orientações para os visitantes.

\section{Resultados e Discussão}

O perfil obtido da trilha 2 é apresentado na Figura 3. Estima-se que a trilha possua cerca de 600 metros na totalidade de seu percurso, do início próximo à Pastoral da Criança até a praia de Itaquitanduva, sendo necessários cerca de 30 minutos para percorrê-la. A trilha é em geral estreita, variando de 0,5 a 1,5 metro de largura. O ponto mais alto do percurso fica na faixa dos 50 metros acima do nível do mar, sendo que os mais baixos estão pouco acima do nível do mar (na praia) e a cerca de 5 metros, próximo à Pastoral da Criança, na entrada do parque.

Durante a primeira visita, a trilha foi subdividida em 6 trechos (sendo o trecho 1 aquele próximo à Pastoral; e o trecho 6 aquele próximo à praia) (Figura 3 ). As principais características de cada trecho foram:

- Trecho 1: predomínio de baixa declividade e trilha estreita, fechada por vegetação de pequeno porte;

- Trecho 2: predomínio de declividade mediana e trilha mais larga, em área menos vegetada;

- Trecho 3: predomínio de declividade mediana, com alguns pontos de declividade mais acentuada, presença de pedras e trilha mais larga, em área menos vegetada;

- Trecho 4: trecho predominantemente plano, densamente vegetado com árvo- 
Trilha ecológica como instrumento de Educação Ambiental: estudo de caso e proposta de adequação no Parque Estadual Xixová-Japuí (SP).

res de grande porte, com solo lamoso e onde há a presença de pedras;

- Trecho 5: predomínio de declividade moderada, densamente vegetado com árvores de grande porte;

- Trecho 6: predomínio de declividade muito acentuada e muitos pontos de erosão do solo, sendo marcado principalmente pela presença de vegetação densa.

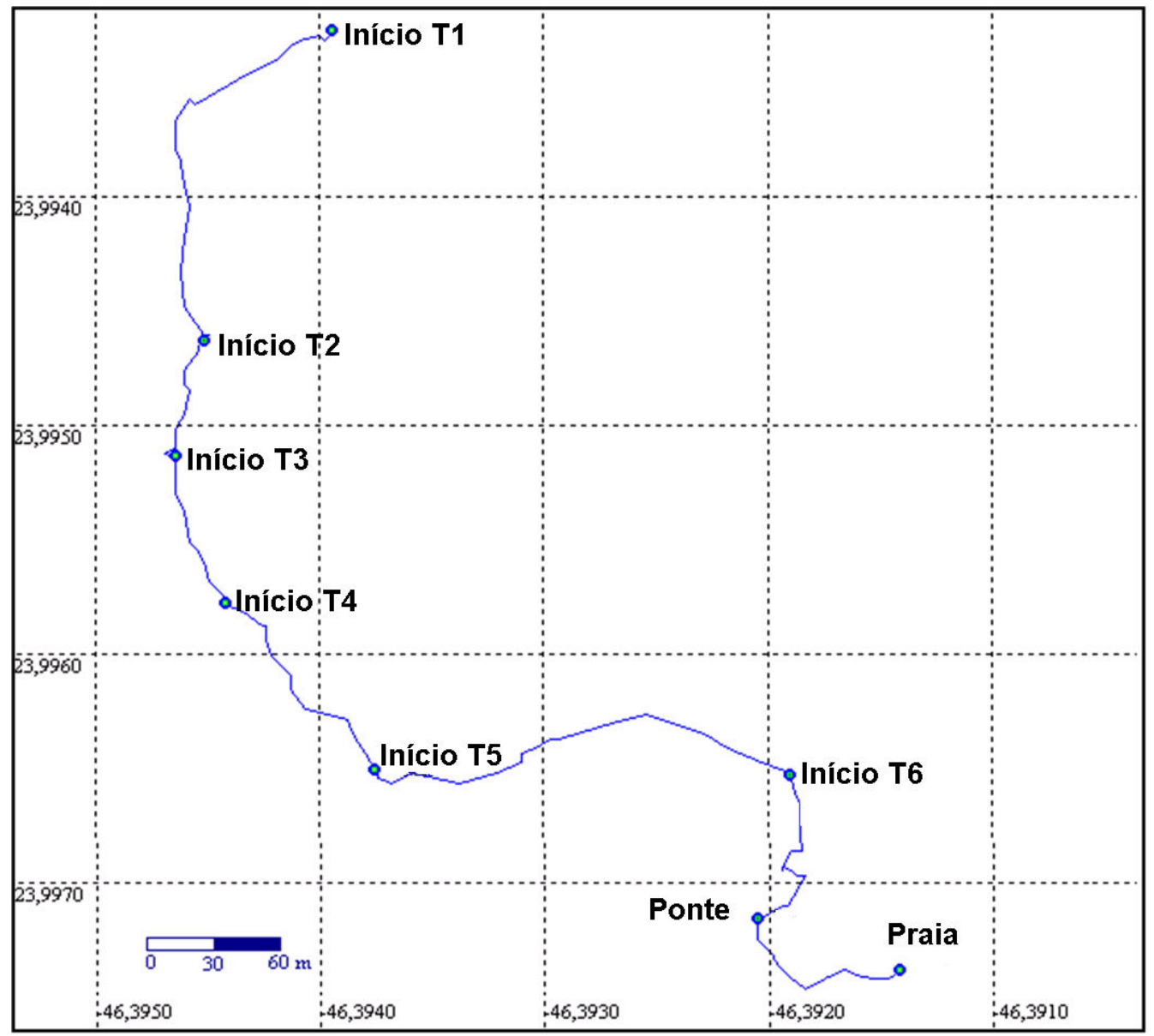

Figura 3. Perfil da trilha 2 e marcação dos seis trechos (T1 a T6), traçado no programa GPS TrackMaker®.

\section{Diagnóstico na visita de Novembro de 2005}

Diversos trechos da trilha apresentavam problemas, podendo ser considerados de baixa comodidade ou de risco para a segurança dos transeuntes. As principais dificuldades encontradas que podem prejudicar os visitantes foram as poças de lama encontradas pelo caminho (Figura 4), os trechos íngremes sem qualquer estrutura de segurança, os canais construídos pela drenagem da água e os barrancos escorregadios (Figura 5). 
Rocha, F.; Barbosa, F.P.; Abessa, D.M.S.

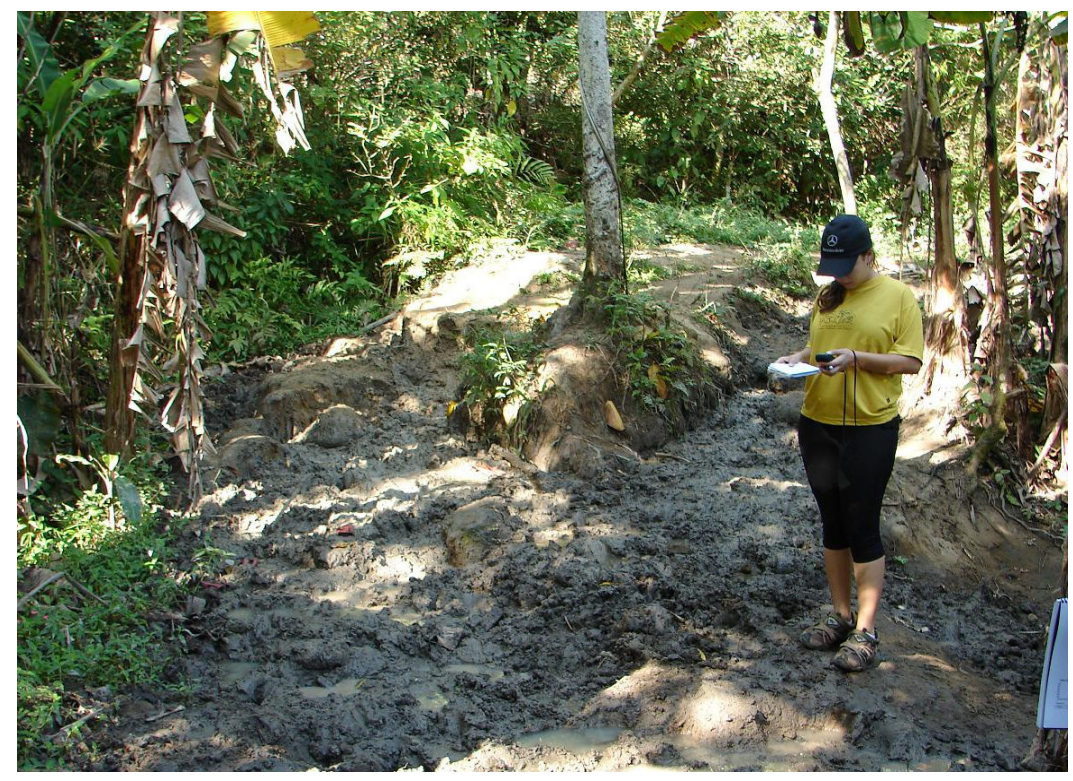

Figura 4. Início da Trilha 2. Notar a erosão e a formação de lama. Foto: F.S.C. Buchmann.

A trilha passa por alguns locais realmente bastante íngremes, com barrancos de solo batido e escorregadio, especialmente no trecho definido como 6. Apenas alguns poucos setores da trilha apresentavam escadas de pedra ou de degraus cortados no barranco, facilitando a caminhada dos transeuntes.

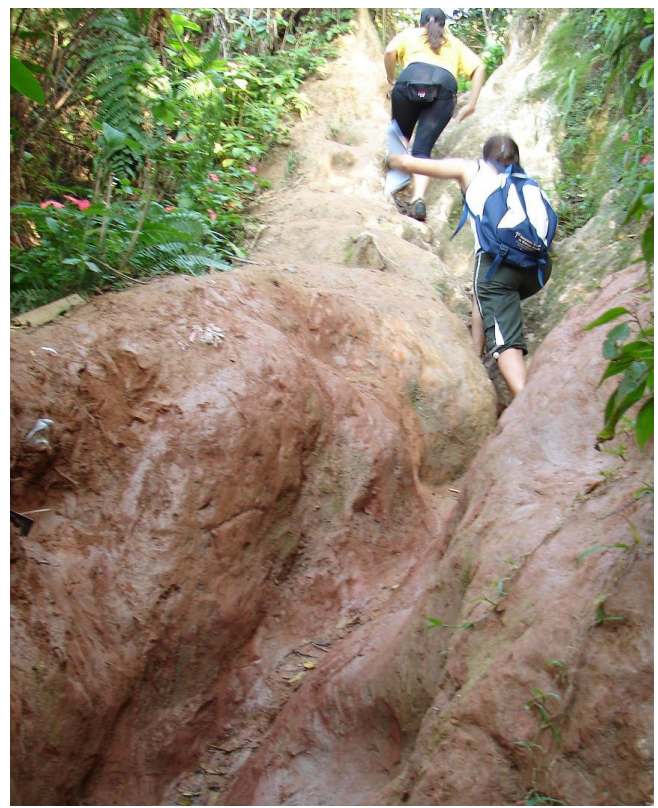

Figura 5. Ponto com erosão e alta declividade encontrado na trilha, no trecho 6. Foto: F.S.C. Buchmann. 
Trilha ecológica como instrumento de Educação Ambiental: estudo de caso e proposta de adequação no Parque Estadual Xixová-Japuí (SP).

Em muitos pontos foram encontradas poças e lamaçais que muitas vezes impossibilitavam a passagem, forçando os transeuntes a invadir a vegetação adjacente e arriscar-se em manobras e saltos para transpor o obstáculo. O problema das poças encontrava-se intensificado pela presença de gado bovino na trilha, já que alguns desses animais foram encontrados no decorrer do percurso (Figura 6). Deve-se salientar que esses animais são exóticos, e podem causar diversos impactos sobre o parque, por meio da herbivoria, da possibilidade de transmissão de doenças, do pisoteio e da geração de resíduos orgânicos nas trilhas. Além disso, podem representar risco aos visitantes desavisados, já que concorrem pela trilha com os visitantes e podem tornar-se agressivos em algumas situações.

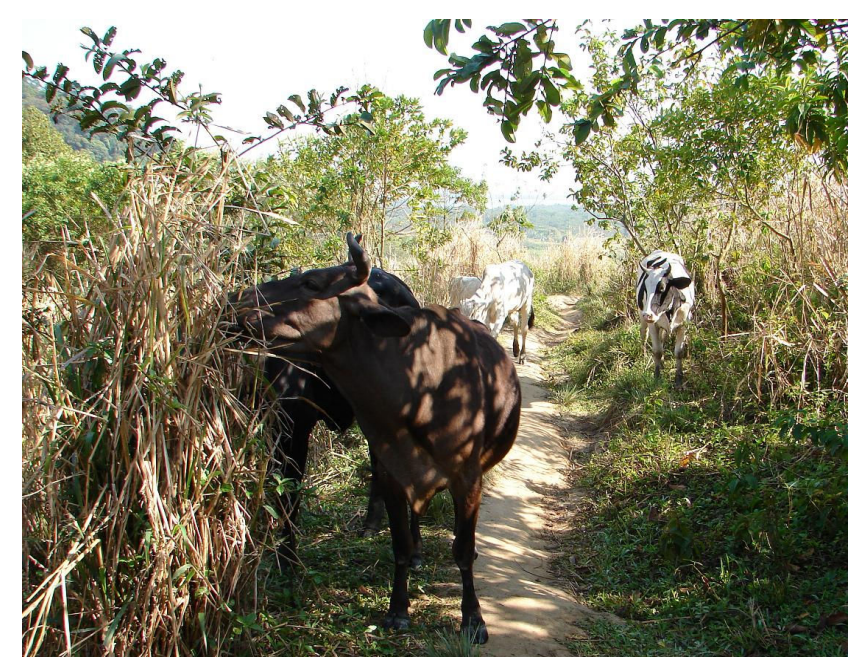

Figura 6. Gado bovino encontrado na trilha. Foto: F.S.C. Buchmann.

Em relação à degradação ambiental, no trecho de trilha que passava pela encosta voltada para o bairro Japuí (trecho 2), o desmatamento encontrava-se muito evidente, com predomínio de vegetação exótica e/ou introduzida. Foram encontradas espécies vegetais invasoras, como bananeiras (Musa paradisiaca), chapéu-de-sol (Terminalia sp), alguns exemplares da Família Asteraceae e predominantemente representantes da Família Poaceae (capim, provavelmente Brachiaria sp). Em alguns trechos também foram encontrados indivíduos típicos de mata secundária, sugerindo que estes locais sofreram devastação no passado e se encontravam em recuperação natural. Destacou-se entre os trechos 2 e 3, por seu elevado grau de degradação, uma grande área descampada, onde foi observada a presença exclusiva de gramíneas. Em muitos pontos foram encontradas entradas para atalhos e caminhos alternativos, já que em alguns locais a trilha não é bem delimitada.

Em toda a trilha, notou-se a inexistência de sinalização, tanto aquela indicativa de direção, quanto de promoção da educação ambiental. Foram encontradas duas placas em todo o percurso. Uma delas, instalada pouco antes da entrada, em uma bica, provavelmente instalada pelos próprios moradores da região, dizia "Ajude-nos a 
conservar a bica. Não use sabão e nem lave objetos gordurosos". A outra placa encontrava-se pendurada em uma árvore, no meio da trilha, e estava extremamente degradada, sendo impossível sua leitura integral. O pequeno trecho compreensível do texto parecia ter a intenção de conscientizar os turistas, principalmente em relação à disposição do lixo, e que indicava que havia sido instalada pela ONG Alma Verde SOS Itaquitanduva.

No percurso integral da trilha, também não havia latões de lixo, sendo que vários resíduos encontravam-se dispostos inadequadamente, principalmente nas encostas dos barrancos. Algumas trilhas secundárias apareciam ao longo do caminho, mostrando que a invasão da mata era um problema no local. Sobre um pequeno curso de água, a passagem era feita por uma ponte estreita e precária, que apresentava algumas tábuas soltas e não possuía corrimões.

\section{Diagnóstico na visita de Setembro de 2006}

A situação da trilha permaneceu praticamente a mesma. Nenhuma alteração parecia ter sido feita por parte da administração ou de uma das ONG no intuito de meIhorar o conforto ou a segurança dos visitantes. No início da trilha, uma nova placa havia sido instalada pela administração do parque, informando a existência do Parque Estadual no local e apresentando alguma alusão às práticas recomendadas em uma UC. A placa instalada na bica pelos moradores encontrada em 2005 havia sido retirada, enquanto a outra placa perdurada em uma árvore no meio da trilha continuava lá, mas em condições ainda piores. A situação da ponte também piorou bastante, sendo que algumas tábuas continuavam soltas e uma delas havia caído (Figura 7). Mais uma vez foi encontrado gado bovino percorrendo a trilha.

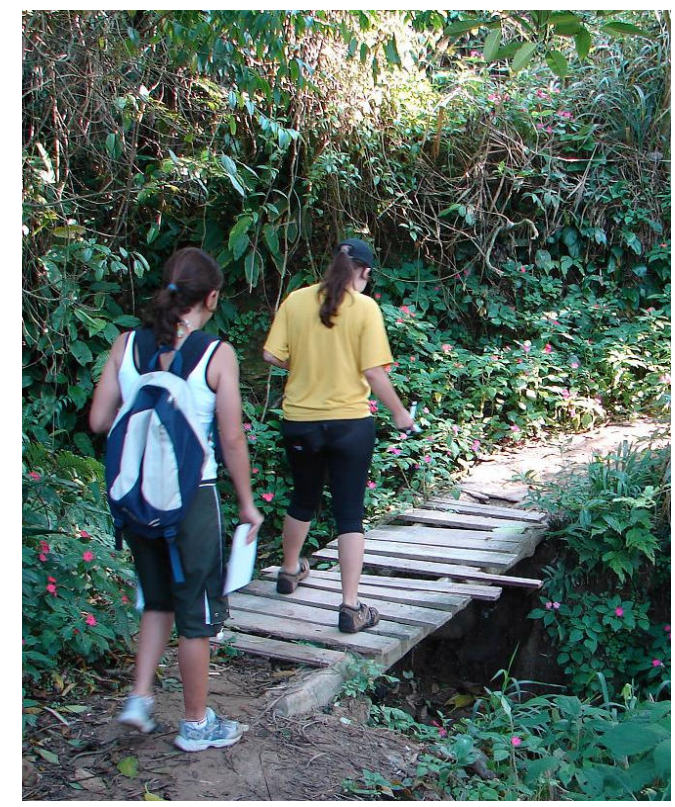

Figura 7. Ponte encontrada na trilha. Notar tábuas soltas e ausentes. Foto: F.S.C. Buchmann. 
Trilha ecológica como instrumento de Educação Ambiental: estudo de caso e proposta de adequação no Parque Estadual Xixová-Japuí (SP).

\section{Diagnóstico na visita de Outubro de 2008}

A situação da trilha piorou visivelmente. Os problemas citados anteriormente estavam agravados, com destaque para os processos erosivos que aumentaram em certos trechos da trilha. Os canais de drenagem encontravam-se muito aprofundados, sendo que em alguns trechos estavam suprimindo o caminho adjacente utilizado pelos visitantes, causando dificuldade de transposição, especialmente nas áreas mais inclinadas. Os barrancos escorregadios e os trechos íngremes estavam ainda mais degradados e com o agravante de ter sido criada uma bifurcação no local indicado na figura 5 , aparentemente após um deslizamento de terra. A ponte indicada no trecho 6 (Figura 7), havia caído e nenhuma estrutura foi implantada para substituí-la, obrigando o visitante a descer até o leito do curso d'água para atravessá-lo.

Entretanto, em relação à degradação ambiental, notou-se uma melhora. A quantidade de lixo na trilha e nas encostas encontrava-se bastante reduzida e a vegetação estava em estágio de regeneração. A área descampada apresentava outras espécies além daquelas encontradas anteriormente, pertencentes basicamente à Família Poaceae. Como reflexo da regeneração da vegetação, toda a triIha estava mais fechada. Muitos dos atalhos encontrados nas visitas anteriores haviam sumido, e uma parte deles ainda permanecia evidente.

Quanto à sinalização, a placa colocada na entrada da trilha em 2006 encontrava-se degradada e parcialmente coberta pela vegetação. A placa da ONG Alma Verde - SOS Itaquitanduva permanecia na árvore no meio da trilha.

Notou-se a atuação da ONG Itaquitanduva Nativa na educação ambiental para os visitantes da trilha, o que não foi percebido nas visitas anteriores. Esta ONG improvisou dois recipientes para coleta de lixo, imediatamente antes do início da trilha, um grande como uma caçamba e outro menor. Em ambos, a ONG pintou frases de educação ambiental solicitando que os visitantes não abandonem seu lixo na praia nem na trilha. A ONG também pintou frases de educação nas paredes da Pastoral da Criança. Sabe-se também que a fiscalização, por parte dos guardas-parque e da polícia ambiental, foi sensivelmente intensificada no período. Portanto, é possível que a combinação de ações de comunicação e fiscalização, tenha contribuído para a redução dos impactos ambientais na trilha. Em sua página na internet, a ONG Alma Verde - SOS Itaquitanduva apresenta alguns projetos de educação ambiental, voltados para os visitantes da trilha.

Por outro lado, o aumento da degradação física da trilha, sobretudo a erosão crescente e a piora na conservação dos poucos equipamentos de infraestrura de apoio presentes, indica que as ações voltadas à manutenção e recuperação da trilha foram deficitárias no período. 


\section{Considerações gerais}

Nas condições atuais, a Trilha 2 não constitui efetivamente um instrumento de educação ambiental e/ou suporte à gestão e conservação do patrimônio natural do PEXJ; ou seja, a trilha tem apenas uma função de fornecer acesso à praia, e mesmo essa função vem sendo cumprida de forma precária, pois seu estado de conservação é ruim, com diversos pontos que dificultam a passagem. A carência de sinalização é um fator que contribui para que os visitantes não sejam conscientizados sobre a importância do espaço em que estão e sobre as restrições de uso existentes.

Um fator complicador é a questão fundiária, pois boa parte da trilha atravessa terrenos ainda sob domínio de proprietários particulares, os quais aguardam suas indenizações ou estão em conflito com o Estado. Nesse sentido, até que as desapropriações sejam efetivadas, com pagamento das indenizações e efetiva regularização fundiária, o órgão gestor tem sua ação limitada, principalmente quanto à execução de obras, instalação de equipamentos e infraestrutura e elaboração de programas de educação e uso público da trilha.

Sendo assim, é urgente que sejam buscados os recursos para regularização da situação da trilha, ao mesmo tempo em que se organizem as ações de correção e adequação, e os estudos necessários para o adequado gerenciamento da trilha. É importante iniciar os planejamentos, considerando as ONG e a população do entorno, visando a capacitação para exploração do ecoturismo controlado nas trilhas, sobretudo na Trilha 2, de modo que o PEXJ possa também reverter em aumento da renda para as comunidades do entorno.

\section{Sugestões de ações para melhoria da Trilha 2}

Devido às más condições dessa trilha, são sugeridas melhorias na infraestrutura de segurança e apoio aos usuários da trilha, tais como corrimões e escadas para facilitar o percurso onde for necessário. Em alguns trechos, a escadaria pode ser feita em pedra ou concreto, ou em madeira, apoiada sobre pilotis, de modo a permitir a recomposição da vegetação, ser pouco invasiva, e incrementar a manutenção do aspecto natural da trilha. Ao mesmo tempo, é preciso instalar um sistema de drenagem da água (calhas), para evitar a formação das canaletas nas margens e no meio da trilha, e para minimizar a ocorrência de poças de lama. É necessária ainda a instalação de lixeiras ao longo de toda a trilha.

Outra sugestão para a melhoria da trilha é a sua delimitação para evitar o alargamento do caminho existente e a abertura de novas trilhas ou de atalhos. Essa delimitação poderia ser feita seguindo os moldes já classicamente utilizados pela Fundação Florestal, com corrimões laterais e contenção de degraus, ambos feitos com madeira. Além disso, os visitantes podem ser instruídos através de placas informativas a escolher sempre a trilha principal e manter-se dentro dela durante todo o percurso.

Idealmente, uma trilha ecológica deve ser feita do modo menos urbanizado 
Trilha ecológica como instrumento de Educação Ambiental: estudo de caso e proposta de adequação no Parque Estadual Xixová-Japuí (SP).

possível, visando o contato com os elementos naturais, porém a garantia da integridade física de quem a percorre deve ser um fator prioritário no seu planejamento (MANNING et al., 1995). Em Pedrini (2006) há uma descrição conceitual sobre a utilização de trilhas ecológicas como ferramentas de educação ambiental e conservação, com base em uma abordagem dialética e transversal. De acordo com esse autor, para que a trilha cumpra seus objetivos, deve contemplar algumas características que serão apresentadas e comentadas a seguir (PEDRINI, op.cit, p.95-96):

- "Abranger um espaço geográfico natural/construído num determinado tempo". Nesse contexto, a Trilha 2 atravessa uma área que em sua maior parte é constituída por Mata Atlântica em estado avançado de regeneração, atingindo uma praia, a qual representa significativo atrativo natural. Além disso, possui conexões com processos históricos, já que sua porção final remonta ao período colonial, quando havia plantações em alguns trechos do parque.

- "Ser planejada para aplicar os pressupostos pedagógicos conceituais da EASS que aperfeiçoa os de Tbilisi". Nesse sentido, devem estar definidos os conceitos de Ecoturismo, Educação Ambiental, Qualidade, e Sociedades Sustentáveis, de modo que as ações de EA estejam direcionadas para a experiência dos visitantes, as mudanças de percepção, e consequentemente de atitude e comportamento.

- "Ser planejada participativamente, incluindo diferentes atores sociais envolvidos na atividade ecoturística, principalmente a comunidade local ou próxima". Em relação a esse aspecto, com a formação do Conselho Gestor do PEXJ, diversas ações de envolvimento com a comunidade local vêm sendo feitas, incluindo sua participação no planejamento da visitação e da EA no parque e seu entorno.

- "Ser monitorada permanentemente com o fim de receber manutenção, atualização e recuperação de seus equipamentos". O PEXJ está realizando a atualização do seu Plano de Manejo e as ações de monitoramento, manutenção e recuperação das trilhas foram consideradas prioritárias. Além disso, há estudo sendo conduzido pela UNESP visando avaliar os aspectos físicos e biológicos relativos às trilhas 1 e 2 .

- "Serem permanentemente avaliados seus impactos antrópicos e naturais e tomadas providências para sua mitigação ou extinção". Os estudos realizados para atualização do Plano de Manejo, assim como aqueles conduzidos de forma complementar já vêm subsidiando o controle dos impactos, embora seja necessário obter um volume maior de recursos para o controle de alguns impactos referentes à visitação, sendo destacada a regularização fundiária, pois a trilha atravessa pontos sob litígio em relação a esse aspecto.

- "Ter seus recursos naturais levantados previamente, componentes abióticos (geodiversidade, metereologia, recursos hídricos, etc) e bióticos 
(biodiversidade) caracterizados taxonômica e ecologicamente, recebendo placas ilustrativas de sua existência com seus nomes científicos e populares". Os recursos já foram mapeados, e hoje há necessidade de discutir com os atores e o próprio Conselho Consultivo do PEXJ, as abordagens de EA a serem aplicadas nas trilhas.

- "Ser o percurso periodicamente alvo de avaliações de seu uso público e impacto natural". Em relação a esse aspecto, há alguns estudos sendo conduzidos, mas é necessário implementar formas mais abrangentes para avaliar o uso público.

Quanto à sinalização, deverão ser colocadas placas informativas no início e no final da trilha, indicando destino, distância, tempo médio necessário para percorrê-la, grau de dificuldade e orientações sobre a preservação do local e sobre comportamentos desejáveis no parque, como, por exemplo, jogar o lixo na lixeira, não acender fogueiras, não coletar plantas nem animais, não acampar, etc. Ao longo da trilha, deverão ser instaladas placas educativas, visando facilitar a interpretação ambiental pelos visitantes. Considerando o contexto regional e as características locais do PEXJ e da própria trilha, sugere-se que os principais temas a serem abordados nas trilhas sejam:

- Interferência Antrópica (em especial no trecho onde a mata foi totalmente suprimida e há gramíneas invasoras, e também no ponto mais alto da trilha, onde é possível visualizar o contraste entre o Parque e a urbanização da região do entorno);

- Sucessão Ecológica (definição, estágio de sucessão em que se encontra o ambiente do parque, ou ao menos o próximo da trilha);

- Botânica (identificação específica, nome comum e principais características de árvores típicas da Mata Atlântica presentes ao longo da trilha, devidamente fixadas nas próprias árvores ou próximas a elas);

- Biodiversidade (definição e importância, além de placas com ilustrações, nomes e características de alguns animais característicos do parque);

- Funções de um parque estadual;

- Regras para o turismo em áreas protegidas;

- Processos ecológicos, bens e serviços ambientais associados ao PEXJ e à mata atlântica.

- Informações sobre o SNUC, na entrada da trilha.

Um resumo dos principais problemas encontrados em cada trecho da trilha encontra-se na Tabela 1. 
Trilha ecológica como instrumento de Educação Ambiental: estudo de caso e proposta de adequação no Parque Estadual Xixová-Japuí (SP).

Tabela 1 - Principais problemas encontrados em cada um dos seis trechos da Trilha 2

\begin{tabular}{|c|c|}
\hline Trecho & Principais Problemas \\
\hline 1 & lama; declividade acentuada; buracos \\
\hline 2 & pontos inclinados \\
\hline 3 & $\begin{array}{c}\text { pontos inclinados e escorregadios; pontos com deslizamento do solo ameaçando } \\
\text { a trilha }\end{array}$ \\
\hline 4 & lama; buracos; pedras soltas \\
\hline 5 & lama; erosão do solo; encostas com riscos de desabamento \\
\hline 6 & encosta de risco; ponto com declividade acentuada e escorregadio; erosão; pon- \\
te destruída; matagal
\end{tabular}

Com base nestes problemas particulares e nos demais encontrados durante 0 presente trabalho, sugere-se as seguintes melhorias, especificadamente para cada trecho apresentado na Figura 3:

- Trecho 1 (do início da trilha até $23^{\circ} 59^{\prime} 38,92183^{\prime \prime}$ S, 46²3'38,61224"W)

- Instalação de placas com as seguintes informações: destino da trilha, extensão e duração do percurso, grau de dificuldade e orientações de preservação e comportamento, SNUC, características do PEXJ;

- Instalação de lixeiras e de estrutura de suporte que permita controlar a entrada e saída de visitantes;

- A presença dos animais exóticos e domésticos é conflitante com os objetivos do parque e deve ser coibida. Nesse caso, sugere-se a instalação de dispositivos simples, tais como um "mata-burro" ou uma cerca,, no início da trilha $\left(23^{\circ} 59^{\prime} 34,06671\right.$ "S, $\left.46^{\circ} 23^{\prime} 36,57729 " W\right)$. O dispositivo auxiliaria a evitar a entrada de bovinos e cavalos na trilha, devendo ser de concreto ou madeira tratada, pois é mais duradouro e permite a passagem mais confortável e segura de pedestres, além de exigir menor manutenção periódica;

- Correção da erosão no solo para evitar a formação de lamaçal na área da entrada da trilha $\left(23^{\circ} 59^{\prime} 34,10895 " \mathrm{~S}, 46^{\circ} 23^{\prime} 36,79364^{\prime W}\right)$ e outros processos erosivos;

- Instalação de degraus e/ou corrimões nas declividades mais acentuadas (235'기, 11950"S, 46²3'39,01871"W);

- Trecho 2 (final do trecho 1 até $23^{\circ} 59^{\prime} 40,70878^{\prime \prime}$ S, 46 $23^{\prime} 39,06546^{\prime \prime} W$ )

- Poucas alterações, além da instalação de degraus em alguns trechos $\left(23^{\circ}\right.$ 59'39,58929"S, $46^{\circ} 23^{\prime} 38,88230^{\prime W}$ ) e de lixeiras. A instalação de placas po- 
Rocha, F.; Barbosa, F.P.; Abessa, D.M.S.

de ser avaliada, considerando orientações técnicas (MAGRO; FREIXÊDAS, 1998).

- Trecho 3 (final do trecho 2 até 2359'43,04581"S, 46²3' 38,25557"W)

- Instalação de degraus e corrimões em alguns trechos e pontos mais inclinados ou lisos, especialmente no ponto sob as coordenadas $23^{\circ} 59^{\prime} 42,24678^{\prime \prime S}$ e 46²3'38,71060"W;

- Correção dos pontos de deslizamento de solo;

- Instalação de lixeiras e placas informativas.

- Trecho 4 (final do trecho 3 até $23^{\circ} 59^{\prime} 45,64626^{\prime \prime} \mathrm{S}, 46^{\circ} 23^{\prime} 35,84612^{\prime \prime} W$ )

- Onde há lama, instalação de plataforma simples de madeira, baseada sobre pilotis (23⒌'45,05604"S, 46²3'36,19976"W)

- Na escada de pedra, instalação de corrimão, colocação de pedra nos buracos e melhoria da fixação das pedras existentes (23⒌'45,64626"S, $46^{\circ}$ $23 ' 35,84612 " \mathrm{~W})$.

- Trecho 5 (final do trecho 4 até $23^{\circ} 59^{\prime} 45,87285^{\prime \prime}$, $46^{\circ} 23^{\prime} 29,24663^{\prime \prime} W$ )

- $\mathrm{Na}$ área apresentando erosão do solo e lama, instalação de plataforma simples de madeira, também sobre pilotis $\left(23^{\circ} 59^{\prime} 44,87980^{\prime \prime S}, 46^{\circ}\right.$ 23'31,03961"W);

- Nas curvas onde são percebidas encostas com grande erosão do solo e risco de desabamento, instalação de corrimão de segurança e sistema de contenção do solo $\left(23^{\circ} 59^{\prime} 44,75790 " S, 46^{\circ} 23^{\prime} 31,64340 " W\right.$ e $23^{\circ} 59^{\prime} 45,12453^{\prime \prime S}$, $46^{\circ} 23$ '32,99069"W).

- Instalação de lixeiras e placas informativas, inclusive alertando para os riscos existentes em áreas íngremes.

- Trecho 6 (final do trecho 5 até $23^{\circ} 59^{\prime} 48,79828^{\prime \prime S}, 46^{\circ} 23^{\prime 2} 27,44821^{\prime \prime} W$ )

- Instalação de guarda-corpo no lado esquerdo da curva onde há uma encosta de risco $\left(23^{\circ} 59^{\prime} 47,19571\right.$ "S, $\left.46^{\circ} 23^{\prime} 29,35465 " \mathrm{~W}\right)$;

- Instalação de escada suspensa com corrimão em parte do trecho, pois o local é bem íngreme, escorregadio e encontra-se sob erosão $\left(23^{\circ}\right.$ $\left.59^{\prime} 47,25847 " \mathrm{~S}, 46^{\circ} 23^{\prime 2} 29,06859 " \mathrm{~W}\right)$;

- Ponte: instalação de uma nova ponte, com projeto adequado e contendo corrimões (23⒌'47,95732"S, 46²3'29,72428"W);

- Limpeza do matagal e reflorestamento no trecho entre a praia e a ponte; 
Trilha ecológica como instrumento de Educação Ambiental: estudo de caso e proposta de adequação no Parque Estadual Xixová-Japuí (SP).

- Instalação de corrimão do lado esquerdo e plantio de uma árvore para conter a erosão, onde se encontra um pequeno barranco $\left(23^{\circ} 59^{\prime} 46,93198 " S, 46^{\circ}\right.$ 23'29,10782"W);

- Instalação de uma placa informativa no início da trilha no lado da praia, semeIhante à sugerida para a entrada da trilha;

- Instalação de placa informando a qualidade das águas da bica (potabilidade) e do mar (balneabilidade);

- Instalação de lixeira.

\section{Conclusão}

As trilhas são ferramentas de educação ambiental muito eficazes, porém, se mal administradas podem se tornar um agravante na degradação ambiental de uma área preservada. As trilhas permitem o acesso às áreas mais interiores da Unidade de Conservação e, por isso, devem ser planejadas e manejadas de modo a maximizar a conscientização ambiental do visitante e minimizar os impactos que estes podem acarretar. Além disso, a segurança dos visitantes é diretamente relacionada às condições da trilha.

A melhoria das trilhas é uma das necessidades mais emergentes do PEXJ, já que envolve a segurança e o bem-estar de seus visitantes, além de constituir uma importante ferramenta para a educação ambiental. Para que sua implementação tenha um efeito mais positivo, é recomendável que sejam desenvolvidos outros projetos no Parque, tais como de capacitação de monitores e de instalação de um Centro de Visitantes. Com o desenvolvimento de uma infra-estrutura completa para o recebimento de visitantes, o PEXJ deverá ser um importante local para recreação e educação ambiental na Baixada Santista, proporcionando interação entre a população e o meio ambiente.

\section{Referências Bibliográficas}

ALMA VERDE SOS Itaquitanduva. Disponível em: www.sositaquitanduva.org.br. Acesso em: 26 out. 2008.

BARROS, M.I.A. Caracterização da visitação, dos visitantes e avaliação dos impactos ecológicos e recreativos do planalto do Parque Nacional do Itatiaia. Dissertação de mestrado, Universidade de São Paulo. Escola Superior de Agricultura Luiz de Queiroz, Piracicaba, 2003, 121p.

BRASIL. Lei Federal n 9.795, de 27 de abril de 1999. Dispõe sobre a educação ambiental, institui a Política Nacional de Educação Ambiental e dá outras providências. Brasília, DF. Ministério do Meio Ambiente / MEC, 1999.

BRASIL. Lei Federal n. 9.985, de 18 de julho de 2000. Regulamenta o art. 225, § 10, incisos I, II, III e VII da Constituição Federal, institui o Sistema Nacional de Unidades de Conservação da Natureza e dá outras providências, 2000.

BUCKLEY, R.; PANNELL, J. Environmental impacts of tourism and recreation in national parks and conservation reserves. Journal of Tourism Studies v.1, n.1, p.24-32, 1990. 
Rocha, F.; Barbosa, F.P.; Abessa, D.M.S.

CIFUENTES, M. Determinación de capacidad de carga turística en áreas protegidas. Turrialba, Costa Rica. World Wildlife Fund. 1992.

EAGLES, P.F.J.; MCCOOL, S.F.; HAYNES, C.D.A. Sustainable Tourism in Protected Areas Guidelines for Planning and Management. IUCN Gland, Switzerland and Cambridge, UK. xv + 183pp. 2002.

FERREIRA, L.E.C. Estudo de Viabilidade de Implantação no Núcleo Pedro de Toledo, Parque Estadual da Serra do Mar - SP. Monografia (Graduação em Ciências Biológicas, habilitação em Gerenciamento Costeiro). Universidade Estadual Paulista Julio de Mesquita Filho, Campus do Litoral Paulista. São Vicente, 2005, 74p.

GOOGLE. Galeria de Imagens, TerraMetrics, 2005. Disponível em: http:// maps.google.com. Acesso em: 15 dez. 2005.

IGC-SP. Instituto Geográfico Cartográfico de São Paulo. Disponível em: http:// www.igc.sp.gov.br/copm_divmun.htm. Acesso em: 05 set. 2007.

MAGRO, T.C. Impactos do Uso Público Em uma Trilha no Parque Nacional do Itatiaia. Tese de Doutorado. Universidade de São Paulo, Escola de Engenharia de São Carlos (Ciências da Engenharia Ambiental). São Carlos, 1999, 135p.

MAGRO, T.C.; FREIXÊDAS, V.M. Trilhas: como facilitar a seleção de pontos interpretativos. Circular Interna IPEF, n.186, 10p., 1998.

MANNING, R.; LIME, D.; HOF, M.; FREIMUND, W. The Visitor Experience and Resource Protection (VERP) Process: The Application of Carrying Capacity to Arches National Park. The George Wright Forum, n.12, n.3, p.41-45, 1995.

MINISTÉRIO DO MEIO AMBIENTE. Diretrizes para Visitação em Unidades de Conservação. Ministério do Meio Ambiente, Secretaria de Biodiversidade e Florestas, Diretoria de Áreas Protegidas: Brasília, DF. 2006. 61p.

OLIVA, A. Programa de Manejo Fronteiras para o Parque Estadual Xixová-Japuí - SP. Dissertação (Mestrado em Recursos Florestais). Universidade de São Paulo. Escola Superior de Agricultura Luiz de Queiros. Piracicaba, SP, 2003, 257p.

OLIVEIRA, R.T.; BLOOMFIELD, V.K.; MAGALHÃES, L.M.S. Trilha auto guiada: proposta de implantação e interpretação na Floresta Nacional Mário Xavier Sandra Regina da Costa. Floresta e Ambiente, v.6, n.1, p.138-143, 1999.

PEDRINI, A. de G. Avaliação da Educação Ambiental no Ecoturismo (com Trilhas): Uma Proposta metodológica de Qualidade Conceitual. Revista OLAM - Ciência e Tecnologia, Rio Claro (SP), v. 7, n.2, p. 84-106, dez/2006.

PEDRINI, A.G.; COSTA, C.; NEWTON, T.; MANESCHY, F.S.; SILVA, V.G.; BERCHEZ, F.; SPELTA, L.; GHILARDI, N.P.; ROBIM, M.J. Efeitos ambientais da visitação turística em áreas protegidas marinhas: estudo de caso na piscina natural marinha, Parque Estadual da Ilha Anchieta, Ubatuba, São Paulo, Brasil. Revista OLAM - Ciência e Tecnologia, Rio Claro (SP), v. 8, n.1, maio/junho 2007. 
Trilha ecológica como instrumento de Educação Ambiental: estudo de caso e proposta de adequação no Parque Estadual Xixová-Japuí (SP).

SÃO PAULO (Estado). Decreto Estadual NN 37.536. Dispõe sobre a criação do Parque Estadual Xixová-Japuí e dá outras providências. Diário Oficial do Estado, 27 de Setembro de 1993, São Paulo, SP, 1993.

. Secretaria do Meio Ambiente. Parque Estadual Xixová-Japuí - Plano de Manejo - Fase 1 - Consolidação de Dados e Diretrizes Complementares. São Paulo: Coordenadoria de Informações Técnicas, Documentação e Pesquisa Ambiental; Instituto Florestal; Instituto de Botânica; CEPEL/UNESP, 1997, 74p.

VASCONCELLOS, J. M. de O. Educação e Interpretação Ambiental em Unidades de Conservação. Cadernos de Conservação, ano 3, n 4. Curitiba, PR. Fundação O Boticário de Proteção à Natureza. 2006. 86p.

\section{Agradecimentos}

Agradecemos ao Dr. Francisco de Sekiguchi de Carvalho e Buchmann e à Dra. Selma Dzimidas Rodrigues, pelo auxílio técnico, à diretoria do PEXJ-IF-SMA, na pessoa do Sr. Eduardo Lourenço da Silva (antigo gestor) e do Sr. Joaquim do Marco Neto (atual gestor), e aos revisores anônimos da Revista Brasileira de Ecoturismo, que forneceram sugestões para o aprimoramento do manuscrito.

Fernanda Rocha: Universidade Estadual Paulista “Julio de Mesquita Filho”, Campus Experimental do Litoral Paulista.

Email: rochaf_bio@yahoo.com.br

Link para o currículo Lattes: http://lattes.cnpq.br/2942639592552911

Fabiana Pestana Barbosa: Universidade Estadual Paulista "Julio de Mesquita Filho", Campus Experimental do Litoral Paulista.

Email: barbosafp@hotmail.com

Link para o currículo Lattes: http://lattes.cnpq.br/6855097494024142

Denis Moledo de Souza Abessa: Universidade Estadual Paulista "Julio de Mesquita FiIho", Campus Experimental do Litoral Paulista

Email: dmabessa@csv.unesp.br

Link para o currículo Lattes: http://lattes.cnpq.br/2842419319556542

Data de submissão: 20 de março de 2010.

Data do aceite: 01 de junho de 2010. 